Session $\underline{3560}$

\title{
Controversial Aspects of the New ABET Criteria and its Implementation
}

\author{
Omid Ansary, Alireza Rahrooh, and Walter W. Buchanan \\ Penn State University/University of Central Florida/Northeastern University
}

\begin{abstract}
This paper will address the problems that are associated with the new ABET criteria. Specifically, it discusses the "a through k" assessment criteria, problems of creating a process and maintaining the infrastructure that is required to validate the outcomes, the cost issues related to the resources engaged in accommodating such a process, and how these issues are anticipated to influence the participation of universities/colleges in such unattractive activities. Moreover, the problem of assessing the assessors, lack of uniformity in evaluation of engineering programs across different colleges and universities (different evaluators may be influenced by their own philosophies of the assessment process, since many of the criteria are either vague and/or loosely stated), and questionable results, since in most cases only one evaluator makes the recommendations regarding the accreditation of a program (this may be caused either by nonavailability of sufficient number of evaluators from ABET or lack of funds from institutions to support visitation of additional evaluators). The authors will explore their personal experiences, using examples that are associated with the foregoing issues.
\end{abstract}

\section{Introduction}

The Engineering Criteria 2000 is an outcome assessment process that requires various criteria for institution seeking accreditation. These criteria include;

Criterion 1. Students

Criterion 2. Program Educational Objectives

Criterion 3. Program Outcomes and Assessment

Criterion 4. Professional Component

Criterion 5. Faculty

Criterion 6. Facilities

Criterion 7. Institutional Support and Financial Resources

Criterion 8. Program Criteria

Although the process and criteria are designed to accredit quality-engineering programs, they have several weaknesses and their implementations demand enormous resources. These weaknesses and required burden on the institutions, which is unattractive economically and administratively, is causing engineering programs across the nation to question the affordability of seeking accreditation through ABET. Furthermore, the quality, quantity, and non-uniformity of the assessors/evaluators have also caused great concerns for institutions seeking accreditation. 
While each of the foregoing criteria share similar concerns, the authors will only concentrate on exploring the issues that are associated with criteria 2 and 3. The questions of the quality, quantity, and non-uniformity of the assessors, using a real scenario, are also discussed. This discussion will then lead to a recommendation that could alleviate some of these problems.

\section{Weaknesses of Criteria 2000}

Criteria 2 and 3, as it appears in ABET's publication on the ASEE web-site, indicate that:

\section{"Criterion 2. Program Educational Objectives}

Each engineering program for which an institution seeks accreditation or reaccreditation must have in place:

(a) detailed published educational objectives that are consistent with the mission of the institution and these criteria

(b) a process based on the needs of the program's various constituencies in which the objectives are determined and periodically evaluated

(c) a curriculum and processes that ensure the achievement of these objectives

(d) a system of ongoing evaluation that demonstrates achievement of these objectives and uses the results to improve the effectiveness of the program.

\section{Criterion 3. Program Outcomes and Assessment}

Engineering programs must demonstrate that their graduates have:

(a) an ability to apply knowledge of mathematics, science, and engineering

(b) an ability to design and conduct experiments, as well as to analyze and interpret data

(c) an ability to design a system, component or process to meet desired needs

(d) an ability to function on multidisciplinary teams

(e) an ability to identify, formulate, and solve engineering problems

(f) an understanding of professional and ethical responsibility

(g) an ability to communicate effectively

(h) the broad education necessary to understand the impact of engineering solutions in a global and societal context

(i) a recognition of the need for, and an ability to engage in life-long learning

(j) a knowledge of contemporary issues

(k) an ability to use the techniques, skills, and modern engineering tools necessary for engineering practice.

Each program must have an assessment process with documented results. Evidence must be given that the results are applied to the further development and improvement of the program. The assessment process must demonstrate that the outcomes important to the mission of the institution and the objectives of the program, including those listed above, are being measured. Evidence that may be used includes, but is not limited to the following: student portfolios, including design projects; nationally-normed subject content examinations; alumni surveys that document professional accomplishments and career development activities; employer surveys; and placement data of graduates." 
The major weakness of criterion 2 is that it is not sensitive to newly developed engineering programs. To elaborate this, in this criterion ABET requires inclusion of the program's various constituencies in developing objectives and curriculum for the program. However, inclusion of some of the major constituencies (such as students and parents) in designing a curriculum and developing objectives for a new program is neither possible nor meaningful. Moreover, a new program that cannot present data regarding their graduates' performances in the workforce is in a great disadvantage in comparison to an already established program. This enforces another problem on a new program to include their stakeholders (e.i., employers and students) in its assessment process for continual improvement. The foregoing argument clearly indicates criterion 2 does not completely fit to a newly developed program.

While many of requirements stated in criterion 3 are reasonable, assessment of criterion 3.f, 3.h, and 3.i are difficult and could be very subjective. This will cause different interpretations among different programs as well as the ABET's evaluators. Although the criteria 2 and 3 clearly focus on accrediting programs that maintain quality of engineering disciplines based on the objectives that are set by the programs, they contain many components that are vague, generic, and lack clear specifications. Such vagueness and generic criteria will cause a wide range of uncertainty as what may define a quality program as well as non-standardization of the objectives set by programs. This could further lead to accrediting programs that do not have strong engineering components, but fulfill their own objectives that satisfy ABET's criteria. This undoubtedly will cause non-uniformity in quality among the accredited programs.

On the other hand, offering a valid academic program is generally part of the infrastructure of most institutions and engineering programs are not exceptions. For example, most institutions include activities similar to ABET's criteria in their strategic plans. The program faculty and administrations are usually charged to monitor these activities to ensure the feasibility and quality of their programs. However, the major difference is that ABET's criteria require enormous documentation, bookkeeping, statistical analyses, data gathering, periodic surveys, and ABET's way of documenting students portfolios on a periodic basis. These require a tremendous amount of resources and burden on programs and institutions. For some engineering disciplines the benefit of being accredited is so minimal that many institutions are questioning their participation in pursuing ABET accreditation at such an undesired cost. For example, the main benefit to graduates from an accredited electrical engineering program is the ability to take the FE and PE examinations. However, most electrical engineers are not required to take such exams.

\section{Assessing The ABET's Evaluation Process}

ABET requires one evaluator to visit and review a program. This evaluator is generally a member of a visiting team that possibly consists of evaluators for other programs within the same institution. This team also has a team leader that coordinates the activities of the evaluators. Very seldom do other members or the team leader protest the recommendations that are made by the assigned evaluator. This perhaps is due to trusting the expertise of the evaluator. However, as it was indicated in the preceding section, many of the criteria are vague and leave 
room for interpretation. Since each evaluator may interpret these criteria based on his/her own understanding, philosophy, belief, and standard, the outcome of the review may be biased. This may result in accreditation for a program, while not accrediting a similar program at another institution by two different evaluators. To explore this further, in a real case scenario that one of the author's programs was the beneficiary in an ABET visit, the evaluator had a major problem with the institution offering both EE and EET in the same department. In fact, despite the institution's effort of presenting each programs' objectives and curriculums as well as exhibiting the distinct differences between the programs, the institution was flagged with a "weakness" in criterion 1 for this by ABET. None of the ABET criteria mention that the engineering and engineering technology are prohibited to coexist within the same department. Additionally, the reviewer did not prepare himself for the visit prior to coming for the site visit, did not review the student portfolios and other material that were presented to him, and flagged the institution with two deficiencies. The first deficiency was removed after the institution provided the pertinent materials to ABET in its later communication (these were exactly the same materials that were available to the reviewer during his visit). The second deficiency, which was mainly on delivery of capstone design, was never removed. Under ABET guidelines, the institution appealed for reconsideration and the decision of "not-to-accredit" was reversed. A portion of the appeal letter is presented next to provide the reader clear understanding of our claim in unjust assessment. Moreover, only the institution's qualification in regard to this deficiency is presented. This includes the way in which the program curriculum is implemented to include design in order to prepare the students for a major design experience and how the major design experience course, Capstone Design course, is delivered. Furthermore, the implementation of ABET's assessment and improvement process is exercised on the delivery of this course. The program has also demonstrated how it has improved this course from the time of reviewers' visit to the their final communication with ABET.

\section{Implementation of Design in the curriculum to prepare students for a major design} experience.

Although the freshman and sophomore engineering courses include design concepts and methodology such as structured programming and open-ended problem solving, the majority of the design emphasis within the electrical engineering program begins in the junior year. Here, beginning with the circuits course sequence, we introduce the students to a variety of circuit design and analysis techniques. We highlight the concept that there is no one right way to solve problems, rather the students will be learning a set of tools which can be used, and the students must decide which is the best way to solve each problem. They are required to design simple circuits for homework. Problem solving is emphasized throughout these courses. Students are encouraged to pursue other sources of solved and unsolved problems from the library. They are also often encouraged to work together as groups on homework solutions, as typically would be expected in industry. In the electrical circuits laboratory, each experiment is structured to require the students to design the experiment to achieve the goals that complement the corresponding course or lectures. Clearly, the ability to design a set of experimental measurements to achieve the specific results is fundamental to engineering practice.

During this year of study, the students are also introduced to design concepts and methodology in signals and systems, electronic devices and circuits, and electronic materials. Here, the problems 
include simple designs that improve the students' grasp of the basic the ory while applying the design notions and tools.

Group design projects provide an opportunity to take on larger, more complex design problems, while giving the students experience in group dynamics. Hints and new design approaches are provided in the lecture and in meetings with the student groups. Cost, size, and complexity tradeoffs are regularly considered as a part of the design process. Design tools are introduced, and documentation standards are emphasized. The microprocessors course continues this treatment by emphasizing the concepts of bottom up (logic design to ALU to CPU design) versus top down design (high level to assembly language code) methodologies. Hardware/software economic tradeoffs are discussed.

The electronics component of the first semester senior year builds on the earlier ideas utilizing more complex designs including power supplies (regulated and unregulated), BJT and FET amplifier designs and the advantages of each, and operational amplifier circuits and applications using the ideal model. Cost tradeoffs are regularly considered as a part of the design process.

Finally, the communications skill course, included in this first semester of the junior year, encourages the students to recognize the importance of being able to present their technical ideas in an organized and coherent manner. In the junior year, the electronic laboratories where the student must build and test a wide variety of designs reinforces electronic circuit design concepts.

The junior year signals and systems analysis course and associated laboratory introduce the fundamentals of signal analysis along with the modeling of signals and systems used in engineering practice. The laboratory introduces the students to the tools that are available for solving the problem and requires a design problem to be completed, which utilizes these tools.

During the second term of the junior year and the senior year, the students are required to complete a number of electrical engineering breadth courses, a set of technical electives, and an electrical engineering design course. These courses build upon the design tools, documentation standards, and open-ended problems solving experiences provided in the earlier courses. Although each of these courses is somewhat different in technical sub-discipline through the associated prerequisite courses, each provides increasingly more complex designs and in some cases more intricate design environments. The engineering design component of the program culminates in a major design experience. Every undergraduate from the electrical engineering program must satisfy a capstone design requirement for graduation. This requirement, which involves design and implementation of a solution to a real problem, provides students with a substantial, complete design experience, including problem definition, investigation of the stateof-the-art, prototype design, implementation, and evaluation.

Overall, we believe that the curriculum provides a comprehensive experience in electrical engineering design that builds upon theoretical concepts, provides ever increasingly more complex open-ended design problems, introduces a number of design methodologies and tools, reinforces the concept of teamwork and emphasizes the importance of documentation. 


\section{Capstone Design Course}

The Capstone Design course requires synthesis of a hardware or software structure to solve a problem, specification of how the structure can be realized, and construction of the solution. The projects allow students to apply the analytical and synthesis skills they have developed during their undergraduate coursework and appreciate how different areas of the curriculum are related to each other. The students also gain practical experience in problem definition, laboratory skills, teamwork and inter-group communication, prototyping techniques, project scheduling, as well as economic, environmental, sustainability, manufacturability, ethical, health and safety, social, and political aspects of engineering practice that are not encountered in other course work.

Capstone design topics may be suggested as a part of the course, but students usually select their own projects. In most cases, students work in a team of two students. An increasing effort is being made to involve students in projects that require a wide range of disciplines, both within electrical engineering and beyond. Some examples of the capstone projects that have been completed in the EE program include:

Bottling System

Consumer Electronics MP3 Player

CAN Bus Controlled Gauge Pack with Microcontroller

Sports Swing Analyzer

Multi-Zone Household Temperature Control System

Building Energy Audit and Corrective Action Plan

Control System Using Power Wiring in Mobile Vehicle Environment

Caller ID with Voice Announcement

Laptop Solar Power Supply

Vehicle Velociometer

Ball Collecting Robot

MP3 Player for an Automobile

PLC/Servo-Controlled Vehicle

Both written and oral reports are presented. Typically, the capstone design project requires:

1) A proposal - Description of the problem and design approach including any special equipment and supplies.

2) A timeline - Specific tasks to be accomplished with milestones identified.

3) A final professional report that follows IEEE publication guidelines - Description and evaluation of the final design.

4) Formal oral presentation at the end of the capstone design course - Held at the end of the spring semester.

We limit enrollment in the capstone design courses to 16 students. At the end of the spring semester, the students present an oral report and demonstrate their capstone projects. All of the faculty and students in the school are invited to this exposition. In addition, companies from the Harrisburg Metropolitan area are often invited to send representatives.

The semester prior to taking the senior capstone design course, students are required to submit a project proposal that meets the course proposal guidelines. These guidelines state, "In well- 
written English prose, describe what you will be designing and building. You must also address the incorporation of engineering standards and realistic constraints in the project that include most of the following considerations: economic; environmental; sustainability; manufacturability, ethical, health and safety, social; and political." To further improve this, we are now offering a one-credit course, entitled "Capstone Design Project Proposal Preparation," the semester prior to the capstone design course. Three faculty members review and critique each proposal to ensure that the appropriate constraints are considered in the capstone project and that the capstone project is manufacturable and realistically meets the time constraints dictated by the semester-long course. Over ninety percent of the Electrical Engineering faculty have over three years of industrial experience. Therefore, when they review project proposals, they have a realistic view of the various types of engineering constraints needed for an engineering project. This review committee may reject or require revision and resubmission of the proposal. After this review, the students revise and resubmit their proposals for further review by the faculty. The Capstone Design course itself requires students to attend two three-hour classes per week. During these hours, the instructor monitors, advises, and critiques the students in their design activities. In this course, students are required to do a weekly oral report and to document their progress in standard engineering notebooks. This activity keeps everyone in the class apprised of their activities as the designs progress.

The capstone design project requires a final oral report and a written report that follows IEEE publication standards for references and format. These reports must also address engineering standards and constraints.

In the capstone design course, students are required to write specifications that emphasize engineering standards and realistic constraints that include most of the following considerations: economic, environmental, sustainability, manufacturability, ethical, health and safety; social; and political. We have also emphasized manufacturability by having the students research and select six vendors who could design and build their projects. The latter is specifically emphasized to ensure that the design is realistic and manufacturable. Attached, we show a sample of the specifications written by students to define their capstone design projects that incorporate engineering standards and constraints. This includes the original and final submissions of the specifications. The original submission is critiqued by the instructor and returned to the students for further improvement. The final submission is graded and critiqued.

The economics or cost of the projects are emphasized by requiring that the students provide a cost analysis for the project that includes not only parts and supply costs, but labor costs as well. Ethics are also stressed by devoting some class time to discussing the IEEE Code of Ethics and how ethics can impact engineering projects.

\section{Conclusions}

Although, we believe most ABET evaluators are well qualified and strive to provide fair evaluations of engineering programs, the foregoing unfortunate scenario should be prevented to ensure the viability of this accreditation agency (although it is understood that this is the responsibility of the team leader/chair, a team leader with expertise in different field within the 
engineering discipline than the program under review may not be able to challenge the evaluator's recommendations, specially when the evaluator has a biased view). Therefore, in order to alleviate this problem, we recommend either of the following:

1. Require more than one evaluator to ensure the quality of assessment and prevention of any misinterpretation of ABET criteria.

2. Require two different group of evaluation teams to visit the institution at different times and have them present their recommendations to ABET independently (realizing this recommendation requires a costly process, an adequately due process would be a less costly alternative).

It is understood that either of these recommendations will add cost to the institution, but this cost is minimal compared to the costs that are already required to establish and maintain an accredited engineering program.

We also recommend that ABET revisit its criteria to accommodate the newly developed programs, standardize program objectives per discipline to ensure uniformity of programs in that discipline nationwide, and provide assessment tools for some of its criteria such as criterion 3.f, 3.h, and 3.i.

Finally, we recommend that ABET put an instrument in place to assess its own evaluation process for continual improvement. Acquiring feedback from its stakeholders (i.e., programs that they visit, including faculty, students, administration, and other stakeholders) after ABET's final recommendations are submitted to the institution under review would help.

\section{BIOGRAPHICAL INFORMATION}

OMID ANSARY is Professor of Electrical Engineering and Director of the School of Science, Engineering and Technology at Pennsylvania State University, Capital College. He received his BSEE from Youngstown State University and his MSEE and Ph.D. from University of Akron. He has numerous publications in various reputable journals and conference proceedings. Omid is senior member of the IEEE and a member of ASEE.

ALIREZA RAHROOH is Associate Professor of Electrical Engineering Technology and Assistant Chair of Engineering Technology at University of Central Florida. He received his BSEE, MSEE and Ph.D. from University of Akron. He has numerous publications in various reputable journals and conference proceedings. Ali is a member of the IEEE and ASEE.

WALTER W. BUCHANAN is Professor of Electrical Engineering Technology and Director of the School of Engineering Technology at Northeastern University. He received his BSE and MSE from Purdue University, and his Ph.D. and J.D. from Indiana University. Walt is a P.E. in five states, and is Past Chair of the Eng. Technology Division of ASEE. He has written 80 papers, and is a Member of TAC of ABET and Past Chair of IEEE's CTAA. 